\title{
Exogenous Application of Salicylic Acid and Nitric Oxide on the Ionic Contents and Enzymatic Activities in NaCl-Stressed Soybean Plants
}

\author{
M. Simaei ${ }^{*}$, R. A. Khavari-Nejad ${ }^{2}$, F. Bernard ${ }^{3}$ \\ ${ }^{1}$ Department of Biology, Lahijan Branch, Islamic Azad University, Lahijan, Iran; ${ }^{2}$ Department of Biology, Research and Science \\ Branch, Islamic Azad University, Tehran, Iran; ${ }^{3}$ Faculty of Biological Sciences, Shahid Beheshti G. C. University, Tehran, Iran. \\ Email: ${ }^{*}$ m.simaei@liau.ac.ir, ra.khavarinejad@gmail.com, f_bernard@sbu.ac.ir
}

Received May $26^{\text {th }}, 2012$; revised June $29^{\text {th }}, 2012$; accepted July $30^{\text {th }}, 2012$

\begin{abstract}
The possible protective role of exogenous SA and NO donor (sodium nitroprusside) against salt stress was examined $\mathrm{NaCl}$-induced oxidative stress in Glycine max L. The results indicated that $\mathrm{NaCl}$-induced ionic toxicity led to significant increase of $\mathrm{Na}^{+}$uptake in root and shoot of soybean, while $\mathrm{K}^{+}$and $\mathrm{Ca}^{2+}$ uptake was decreased markedly. Application of SA, SNP and the combination of SA with SNP inhibited $\mathrm{Na}^{+}$uptake, but improved $\mathrm{K}^{+}$and $\mathrm{Ca}^{2+}$ uptake. Under $\mathrm{NaCl}$ salinity, germination percentage (GP) was decreased significantly as compared with control plants. Moreover, the activity of lipoxygenase (LOX) was increased by $\mathrm{NaCl}$, while the application of SA, NO and SA + SNP could decrease LOX activity in this condition. As well, activities of the polyphenol oxidase (PPO) and phenylalanine ammonia lyase (PAL) were significantly decreased by $100 \mathrm{mM} \mathrm{NaCl}$, while the application of exogenous $\mathrm{SA}$ and $\mathrm{NO}$ increased the activities of PPO and PAL. In addition, it was observed that the SA and NO have effective functions in decreasing the damages induced by $\mathrm{NaCl}$ salinity. The seeds of G. $\max \mathrm{cv}$. Union $\times$ Elf (called L17) were obtained from the Institute of Sapling and Seed in Tehran and experiments have been done in Science and Research Branch, Islamic Azad University. After treatment with SA, SNP and $\mathrm{NaCl}$, the plants were harvested for the estimation of ionic contents and assay of enzyme activities. The results showed that SA and NO act synergistically to reduce the damaging effects of salt tress via enhancing the activity of antioxidative systems.
\end{abstract}

Keywords: Nitric Oxide; Oxidative Stress; Salicylic Acid; Salinity; Soybean

\section{Introduction}

Soybean is an important dicot crop due to the high content of oil and protein in its seeds. Moreover, soybean is subject to abiotic stresses that reduce its yield like many crops. Salinity is one of the most widespread agricultural problems in arid and semi-arid regions that make fields unproductive, and soil salinization is a serious problem in the entire world [1]. Salt stress severely inhibits plant growth for two reasons: first by an osmotic or waterdeficit effect of salinity and second by a salt-specific or ion-excess effect of $\mathrm{NaCl}$. Adaptation to salt stress requires alterations in gene expression and also the application of exogenous substances including salicylic acid and nitric oxide. The molecules such as salicylic acid and nitric oxide donor have been suggested as signal transducers or messengers. These substances have obtained particular attention because of inducing protective effects on plants under $\mathrm{NaCl}$ salinity [2].

*Corresponding author.
Salicylic acid (SA) is a signaling molecule in plants and induces plant tolerance against various biotic and abiotic stresses [3]. SA also plays an important role in the regulation of some physiological processes in plants such as effects on growth and development, ion uptake and transport and membrane permeability [4]. Exogenous SA alters the activities of antioxidant enzymes and increases plant tolerance to abiotic stress by decreasing generation of ROS [2,3]. It has been found that SA has different effects on stress adaptation and damage development of plants that depend on plant species, concentration, method and time of SA application [5]. Furthermore, SA is a potential non-enzymatic antioxidant and an important signal molecule for modifying plant responses to environmental stressors. Some earlier reports display that exogenous SA can ameliorate the impairing effects of drought stress in wheat [6] and salt stress in maize and wheat [7].

Nitric oxide (NO) is another signaling molecule, which plays the important role in a variety of physiological 
processes such as growth and adaptive responses to environmental stress [8]. In relation to abiotic stresses, it was shown that the application of NO donor, SNP reduces harmful effects of salinity [9] and heavy metals on plants [8]. However, nitric oxide itself is a reactive nitrogen species, and studies have shown that its effect on different cells is either protective or toxic, depending on its concentration and on the position of action [10]. Furthermore, $\mathrm{NO}$ as an antioxidant agent can scavenge ROS, also as a signaling molecule leading to alterations of antioxidative gene expression and thus protects plant cells from oxidative damage [8]. NO one can be generated non-enzymatically, by the chemical breakdown of NO donor molecules, such as sodium nitroprusside (SNP), Snitroso-N-acetylpenicillamine, S-nitrosoglutathione (GSNO) and 3-morpholinosydnomine.

\section{Materials and Methods}

\subsection{Plant Growth and Treatment}

Seeds of soybean (Glycine max L. cv. Union $\times$ Elf) were surface-sterilized with $0.5 \%(\mathrm{v} / \mathrm{v})$ sodium hypochlorite for $5 \mathrm{~min}$ and then washed thoroughly several times with sterile distilled water. Sterilized G. max seeds were placed between two layers of filter paper in petri dishes containing water and kept at $25^{\circ} \mathrm{C}$. After germination, 7day-old seedlings were cultivated in a hydroponics system in a growth chamber (Hoagland solution, a 14-h light, day/night temperatures of $25^{\circ} \mathrm{C} / 20^{\circ} \mathrm{C}$, photon flux density $300 \mu \mathrm{M} \cdot \mathrm{m}^{-2} \cdot \mathrm{s}^{-1}$ at the leaf level and $70 \%$ relative humidity).

Before application of $\mathrm{NaCl}$ salinity and nitric oxide donor, seedlings were pretreated with SA $(0$ and $100 \mu \mathrm{M})$ for a week. Sodium chloride ( 0 and $100 \mathrm{mM})$ without or with SNP $(0$ and $100 \mu \mathrm{M})$ was added to Hoagland solution during the third week of seedling growth. SNP (Merck, Germany) was used as a donor of NO. The Hoagland solution was daily renewed and $\mathrm{pH}$ was adjusted close to 6.5 [11]. The control plants have only been treated with sterile distilled water.

After pre-treatment with SA and then treatment with SNP and $\mathrm{NaCl}$, the plants were harvested and the roots and shoots were separated and washed with deionized distilled water. For the estimation of $\mathrm{Na}^{+}, \mathrm{K}^{+}$and $\mathrm{Ca}^{2+}$ contents, the plants were dried at $70^{\circ} \mathrm{C}$ for $48 \mathrm{~h}$. For assay of enzyme activities, determination of flavonoids and anthocyanins concentration and also protein content. Fresh plant materials were frozen in liquid nitrogen and stored at $-70^{\circ} \mathrm{C}$ until use.

\subsection{Analysis of $\mathrm{Na}^{+}, \mathrm{K}^{+}$and $\mathrm{Ca}^{2+}$ Contents}

The dried roots and shoots were wet-ashed in $\mathrm{HNO}_{3}$ and
$\mathrm{HCl}$ solution $(5: 1 ; \mathrm{v} / \mathrm{v})$. The $\mathrm{Na}^{+}$and $\mathrm{K}^{+}$contents of plant tissue were assayed by flame emission spectrophotometry (Model 410, Sherwood Company) and $\mathrm{Ca}^{2+}$ concentration was also measured by atomic absorption spectrophotometry (Spectra A-200, Varian Australia). The contents of these cations expressed as $\left[\mathrm{mg} \cdot \mathrm{g}^{-1}(\mathrm{~d} . \mathrm{m})\right]$.

\subsection{Germination Percentage}

Germination studies were conducted in incubators with a 14-h photoperiod (Gallekan Sanyong Model with cool white fluorescent lamps, $25 \mathrm{mM} \cdot$ photons $\cdot \mathrm{m}^{-2} \cdot \mathrm{s}^{-1}$ photosynthetically active radiation). Twelve treatments, including three levels of $\mathrm{NaCl}(0$ and $100 \mathrm{mM})$, two levels of SA $(0$ and $100 \mu \mathrm{M})$ and two levels of SNP ( 0 and 100 $\mu \mathrm{M})$ were used in this experiment. When no seeds germinated in a treatment, it was considered that germination had completed for that treatment. Finally, the seeds were checked every $24 \mathrm{~h}$ for $3 \mathrm{~d}$. The germination index was estimated using the following equation [12].

$$
G P=\left(\frac{N^{\prime}}{N}\right) \times 100
$$

In this formula, $N^{\prime}$ is the number of germinated seeds and $N$ is the number of used seeds in each petri dish.

\subsection{Flavonoids and Anthocyanins Concentration}

Flavonoids were extracted from $0.1 \mathrm{~g}$ of freshly collected leaves by $10 \mathrm{ml}$ acetic ethanol. Concentration of flavonoids was determined according to the formula described by Krizek et al. [13] and read at $300 \mathrm{~nm}$.

$$
C=(A B S \times V) /\left(\sum \times 1000\right)
$$

In this formula, $C$ is the content of flavonoids in $V \mathrm{ml}$ solution, $A B S$ is the absorbance at $300 \mathrm{~nm}$ and $\Sigma$ is the correction coefficient. Anthocyanins were extracted from leaf (100 mg fresh weight) by $10 \mathrm{ml}$ acetic methanol. Concentrations of anthocyanins were determined according to the method of Wagner [14] and read at 300 $\mathrm{nm}$. The amount of flavonoids and anthocyanins were expressed as $\left[\mathrm{mg} \cdot \mathrm{g}^{-1}\right.$ (f.m.) $]$.

\subsection{Assay of Enzyme Activities}

Frozen leaf samples $(0.5 \mathrm{~g})$ were used for protein extraction according to the method of Bradford [15]. Samples were ground in $5 \mathrm{ml}$ of $50 \mathrm{mM}$ phosphate buffer ( $\mathrm{pH} 7.5$ ) using pre-chilled mortar and pestle. The phosphate buffer contained $1 \mathrm{mM}$ EDTA, $1 \mathrm{mM}$ PMSF and 1\% PVP-40. Then the extract was centrifuged at $4{ }^{\circ} \mathrm{C}$ at $15,000 \times \mathrm{g}$ for $30 \mathrm{~min}$. The supernatant (protein extract) was used for measurement of protein content, the activity of SOD and PPO activity. 


\subsubsection{Lipoxygenase (LOX, EC 1.13.11.12)}

Activity was estimated according to the method of Doderer and coworkers [16]. For measurement of LOX activity, the substrate solution was prepared by adding 35 $\mu \mathrm{L}$ linoleic acid to $5 \mathrm{ml}$ distilled water containing $50 \mu \mathrm{L}$ Tween-20. After adjusting the $\mathrm{pH}$ to $6.5,0.1 \mathrm{M}$ phosphate buffer ( $\mathrm{pH}$ 6.5) was added to make a total volume of $100 \mathrm{ml}$. LOX activity was determined by adding 50 $\mu \mathrm{L}$ of enzyme extracts to $2.95 \mathrm{ml}$ substrate. The solution absorbance was recorded at $234 \mathrm{~nm}$ and the activity was calculated using the extinction coefficient $\left(25 \mathrm{mM}^{-1} \cdot \mathrm{cm}^{-1}\right)$ and expressed as units $(1 \mu \mathrm{mol}$ of substrate oxidized per minute) per mg protein.

\subsubsection{Superoxide Dismutase (SOD, EC 1.15.1.1)}

Superoxide Dismutase (SOD, EC 1.15.1.1) activity was measured using the method of Giannopolitis and Reis [17]. The reaction solution ( $3 \mathrm{~mL}$ ) contained $75 \mu \mathrm{M}$ NBT, $1.3 \mu \mathrm{M}$ riboflavin, $13 \mathrm{mM}$ methionine, $0.1 \mathrm{mM}$ EDTA, $50 \mathrm{mM}$ phosphate buffer $(\mathrm{pH} 7.8)$, and $100 \mu \mathrm{L}$ of the enzyme extracts. The absorbance of the irradiated solution was read at $560 \mathrm{~nm}$ using a spectrophotometer. One unit of SOD activity was defined as the amount of enzymes that inhibited photoreduction of $50 \% \rho$-nitro blue tetrazolium chloride (NBT).

\subsubsection{Polyphenol Oxidase (PPO, EC 1.14.188.1)}

Polyphenol Oxidase (PPO, EC 1.14.188.1) activity was determined according to the method of Raymond et al. [18] at $430 \mathrm{~nm}$ and expressed as $\left[\Delta \mathrm{A}_{430} \mathrm{mg}^{-1}\right.$ (protein) $\left.\min ^{-1}\right]$.

\subsubsection{Phenylalanine Ammonia Lyase (PAL, 4.3.1.5)}

To measure the activity of this enzyme, $0.1 \mathrm{~g}$ fresh root and leaves of soybean were homogenised with $\beta$-mercap- toethanol (15 mM), Tris- $\mathrm{HCl}(\mathrm{pH} 8.2,100 \mathrm{mM})$. The formation of trans-cinnamic acid was monitored at 290 $\mathrm{nm}$. PAL activity is defined as the amount of enzymes forming $1 \mathrm{nmol}$ of trans-cinnamic acid from the substrate phenylalanine and expressed as $\mu \mathrm{mol}$ cinamic acid $\mathrm{mg}^{-1}$ protein [19].

All spectrophotometric analyses were conducted at $25^{\circ} \mathrm{C}$ with a UV-vis spectrophotometer (Model UV-2101 PC, Shimadzu, Japan).

\subsection{Statistical Analysis}

Data for germination, cation content, flavonoids and anthocyanins concentration; and the activities of SOD, LOX, PPO and PAL were analysed using ANOVA (completely randomized) to determine if significant differences were present among means. A Duncan's multiple range tests were carried out to determine if significant $(P<0.05)$ differences occurred between individual treatments (SPSS16).

\section{Results}

\section{1. $\mathrm{Na}^{+}, \mathrm{K}^{+}$and $\mathrm{Ca}^{2+}$ Contents}

Application of $\mathrm{NaCl}(100 \mathrm{mM})$ to $G$. max increased the $\mathrm{Na}^{+}$concentration of shoot and root as compared with control plants, while reduced the $\mathrm{K}^{+}$content in the same conditions (Table 1). Accumulation of $\mathrm{Na}^{+}$in the root of soybean seedlings is more than of shoot. The results indicated that $\mathrm{Na}^{+} / \mathrm{K}^{+}$ratio of root and shoot was enhanced 4.1 and 5.2 times more than of control in the presence of $100 \mathrm{mM} \mathrm{NaCl}$, respectively. As it is shown in the table, the application of SA, NO donor and SA + SNP decreased the $\mathrm{Na}^{+}$content of shoot under salt stress, but they had no effect on the $\mathrm{Na}^{+}$content of root. In the presence of salt

Table 1. Effects of SA, SNP, and SA + SNP supply on Na and $\mathrm{K}$ contents, and $\mathrm{Na} / \mathrm{K}$ ratio of root and shoot in soybean plants under saline and non-saline conditions.

\begin{tabular}{|c|c|c|c|c|c|c|c|c|}
\hline \multicolumn{3}{|c|}{ Treatment } & \multicolumn{2}{|c|}{$\begin{array}{c}\mathbf{N a}^{+} \\
{\left[\mathrm{mg} \cdot \mathrm{g}^{-1} \text { d.m. }\right]}\end{array}$} & \multicolumn{2}{|c|}{$\begin{array}{c}\mathbf{K}^{+} \\
{\left[\mathrm{mg} \cdot \mathrm{g}^{-1} \text { d.m. }\right]}\end{array}$} & \multicolumn{2}{|c|}{$\mathrm{Na}^{+} / \mathrm{K}^{+}$} \\
\hline $\begin{array}{l}\mathrm{NaCl} \\
{[\mathrm{mM}]}\end{array}$ & $\begin{array}{c}\text { SA } \\
{[\mu \mathrm{M}]}\end{array}$ & $\begin{array}{l}\text { SNP } \\
{[\mu \mathrm{M}]}\end{array}$ & Root & Shoot & Root & Shoot & Root & Shoot \\
\hline \multirow{4}{*}{$\mathbf{0}$} & \multirow{2}{*}{ 0 } & $\mathbf{0}$ & $0.34 \pm 0.06 \mathbf{a}$ & $0.157 \pm 0.03 \mathbf{b c}$ & $65.9 \pm 3.2 \mathrm{c}$ & $43.9 \pm 3.1$ cde & $0.0052 \pm 0.0012 \mathbf{a}$ & $0.0030 \pm 0.0047 \mathbf{a}$ \\
\hline & & 100 & $0.25 \pm 0.03 \mathbf{a}$ & $0.179 \pm 0.04 \mathbf{a}$ & $65.9 \pm 2.2 \mathbf{c}$ & $45.2 \pm 0.1$ de & $0.0049 \pm 0.0006 \mathbf{a}$ & $0.0078 \pm 0.0018 \mathbf{a}$ \\
\hline & \multirow{2}{*}{100} & $\mathbf{0}$ & $0.34 \pm 0.01 \mathbf{a}$ & $0.079 \pm 0.01 \mathbf{a b}$ & $44.0 \pm 3.0 \mathbf{b}$ & $43.8 \pm 3.0$ cde & $0.0078 \pm 0.0009 \mathbf{a}$ & $0.0018 \pm 0.0017 \mathbf{a}$ \\
\hline & & 100 & $0.32 \pm 0.02 \mathbf{a}$ & $0.06 \pm 0.03 \mathbf{a b}$ & $52.3 \pm 3.0 \mathbf{b}$ & $43.9 \pm 3.1 \mathbf{e}$ & $0.0061 \pm 0.0008 \mathbf{a}$ & $0.0011 \pm 0.0111 \mathbf{a}$ \\
\hline \multirow{4}{*}{100} & \multirow{2}{*}{$\mathbf{0}$} & $\mathbf{0}$ & $0.81 \pm 0.02 \mathbf{b}$ & $0.572 \pm 0.03 \mathbf{f}$ & $19.6 \pm 0.5 \mathbf{a}$ & $20.1 \pm 0.9 \mathbf{a}$ & $0.0213 \pm 0.0001 \mathbf{c}$ & $0.0273 \pm 0.0040 \mathbf{c}$ \\
\hline & & 100 & $0.73 \pm 0.09 \mathbf{b}$ & $0.43 \pm 0.04 \mathbf{e}$ & $46.8 \pm 3.8 \mathbf{b}$ & $35.7 \pm 3.3 \mathbf{b c}$ & $0.0155 \pm 0.0006 \mathbf{b}$ & $0.0112 \pm 0.0215 \mathbf{b}$ \\
\hline & \multirow{2}{*}{100} & $\mathbf{0}$ & $0.62 \pm 0.07 \mathbf{b}$ & $0.321 \pm 0.03 \mathbf{d}$ & $44.0 \pm 2.9 \mathbf{b}$ & $28.5 \pm 3.1 \mathbf{b}$ & $0.0143 \pm 0.0026 \mathbf{b}$ & $0.0126 \pm 0.0256 \mathbf{b}$ \\
\hline & & 100 & $0.62 \pm 0.07 \mathbf{b}$ & $0.213 \pm 0.04 \mathbf{c}$ & $46.8 \pm 3.8 \mathbf{b}$ & $38.4 \pm 1.8 \mathbf{c d}$ & $0.0132 \pm 0.0004 \mathbf{b}$ & $0.0047 \pm 0.0141 \mathbf{a}$ \\
\hline
\end{tabular}

Notes: Means \pm SE were calculated from three replicates. The significance of difference between treatments was determined by Duncan's test. 
stress, treatment with SA + SNP could reduce the shoot $\mathrm{Na}^{+}$content more than of SA and NO donor alone. As indicated in table, treatment of seedlings with SA, SNP and $\mathrm{SA}+\mathrm{SNP}$ pronouncedly increased the $\mathrm{K}^{+}$concentration in soybean root and shoot subjected to $100 \mathrm{mM}$ $\mathrm{NaCl}$. The ratio of the shoot $\mathrm{Na}^{+} / \mathrm{K}^{+}$decreased by SA, NO donor and especially SA + SNP in the presence of salinity.

The content of shoot and root $\mathrm{Ca}^{2+}$ was significantly decreased in the presence of $\mathrm{NaCl}$ salinity (Figure 1). The data have been supported that using SA with SNP enhanced the content of the root and shoot $\mathrm{Ca}^{2+}$ of soybean seedlings in the medium containing of $\mathrm{NaCl}$, while the application of SA or NO could not be effective.

\subsection{Germination Percentage}

Figure 2(a) demonstrates the inhibitory effects of $\mathrm{NaCl}$ on the germination of soybean seeds. In this experiment, germination of seeds at $100 \mathrm{mM} \mathrm{NaCl}$ was decreased by $25 \%$, respectively, as compared with the control in the absence of $\mathrm{NaCl}$. The role of SA, NO donor and their interaction in controlling the germination of G. max was studied seeds under salinity. Application of SA or NO donor could significantly enhance germination under $\mathrm{NaCl}$ stress. Also, the combination of SA with SNP elevated it in the presence of $100 \mathrm{mM} \mathrm{NaCl}$ (Figure 2(a)).

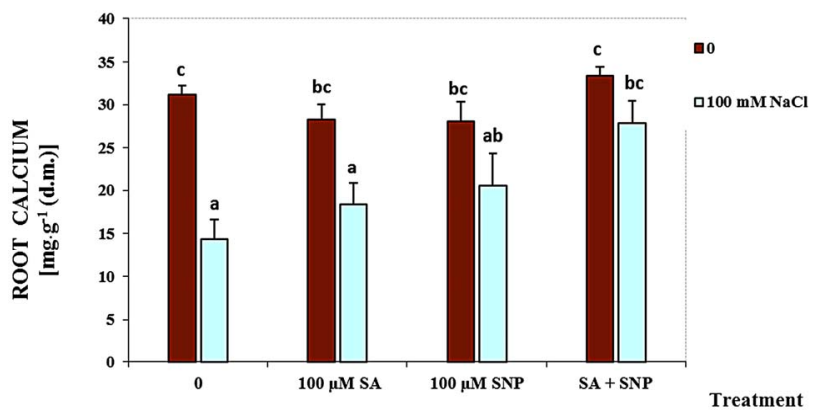

(a)

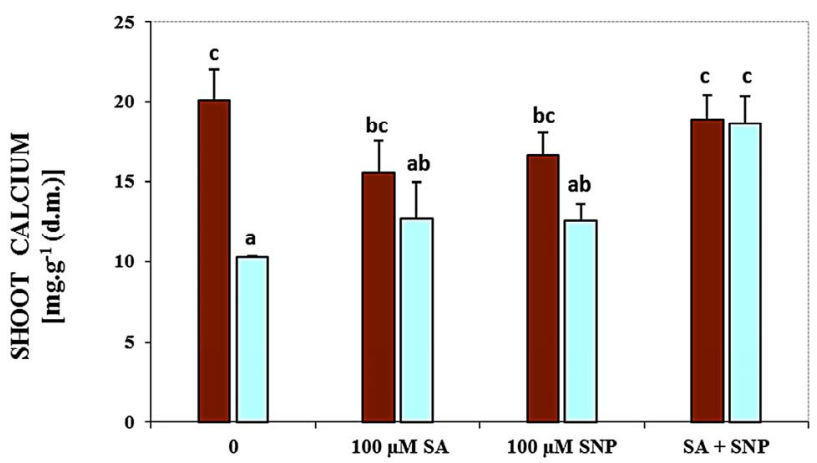

(b)

Figure 1. Effects of SA, SNP, and SA + SNP on the amount of root $\mathrm{Ca}^{+2}$ (a) and shoot $\mathrm{Ca}^{+2}(\mathrm{~b})$ in soybean under saline and non-saline conditions.

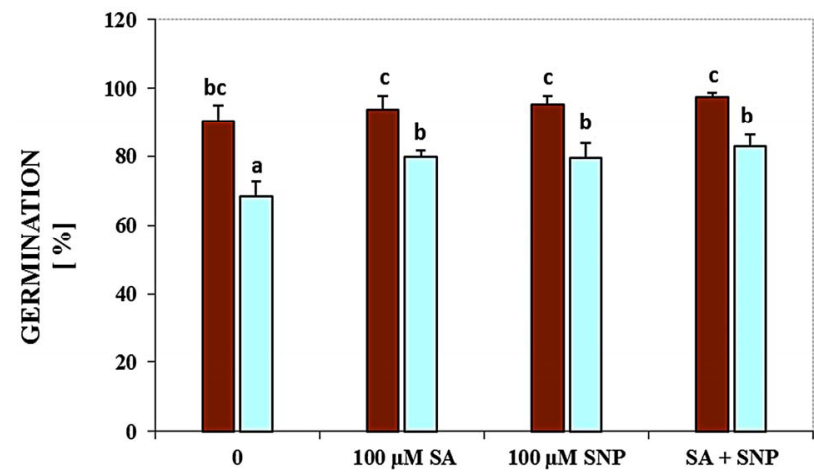

(a)

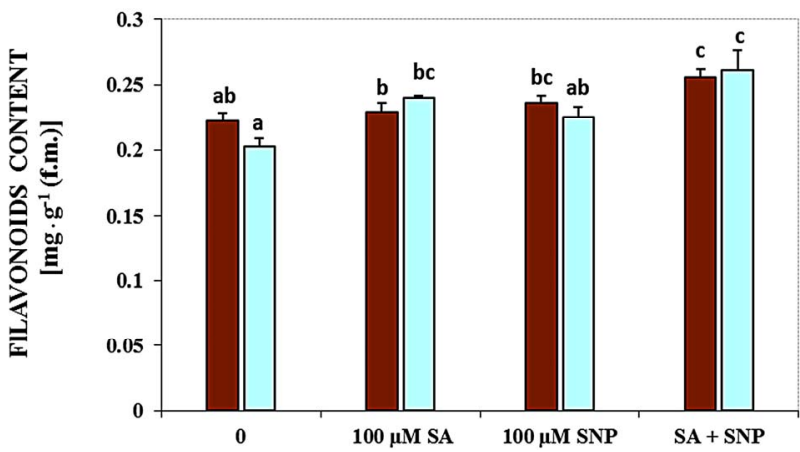

(b)

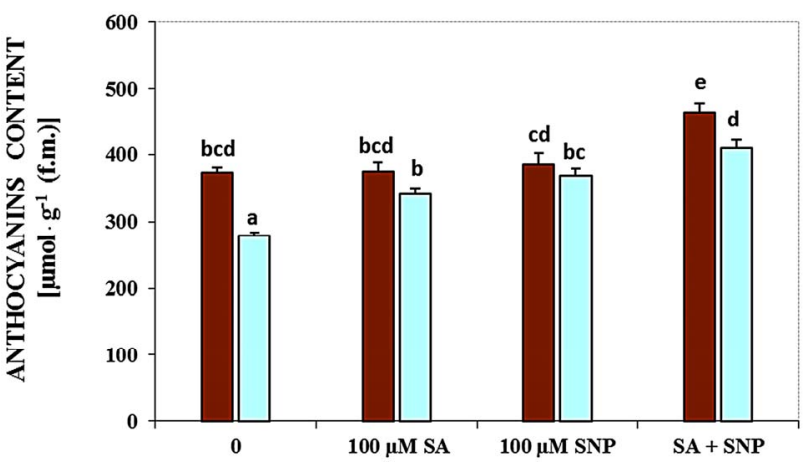

(c)

Figure 2. Effects of SA, SNP, and SA + SNP on germination (a) the contents of flavonoids and anthocyanins $(b, c)$ in soybean under saline and non-saline conditions.

\subsection{Flavonoids and Anthocyanins Concentration}

Salinity induced by $\mathrm{NaCl}$ decreased the contents of flavonoids (Figure 2(b)). In this experiment, treatment with $\mathrm{SA}+\mathrm{NO}$ in the absent medium of $\mathrm{NaCl}$ and in the presence of $100 \mathrm{mM} \mathrm{NaCl}$ increased concentration of flavonoids markedly.

Measurement of G. max anthocyanins content under salinity conditions indicated that salinity reduced the contents of these pigments. As shown in Figure 2(c), the effect of salinity in decreasing anthocyanins was obvious. The application of NO donor or SA and their combina- 
tion elevated the content of anthocyanins in the present of $100 \mathrm{mM} \mathrm{NaCl}$.

\subsection{Enzyme Activities}

About the role of enzymes, in this research the activity of LOX, SOD, PPO and PAL enzymes was measured in $G$. max leaves under various treatments (Figure 3). As shown in Figure 3(a), treatment with $100 \mathrm{mM} \mathrm{NaCl}$ caused a significant increase in the activity of LOX. The activity of this enzyme was decreased by NO donor and SA + SNP exposed to $100 \mathrm{mM} \mathrm{NaCl}$. The activity of SOD enzyme was considerably declined in response salinity stress as compared with control (Figure 3(b)). Application of SA in the present of salinity and the interaction of SA with SNP under saline and non-saline conditions enhanced SOD activity significantly.

Figure 3(c) demonstrates that salt stress pronouncedly decreased the activity of polyphenol oxidase, while the exogenous application of SA, SNP and SA + SNP in the absent salinity and in the presence of $\mathrm{NaCl}$ stress markedly increased the activity of this enzyme. Therefore, the addition of SA, SNP and SA + SNP was significantly enhanced PPO activity under non-saline conditions in comparison to control plants. The results have been data in Figure 3(d) showed that in G. $\max$, the activity of PAL

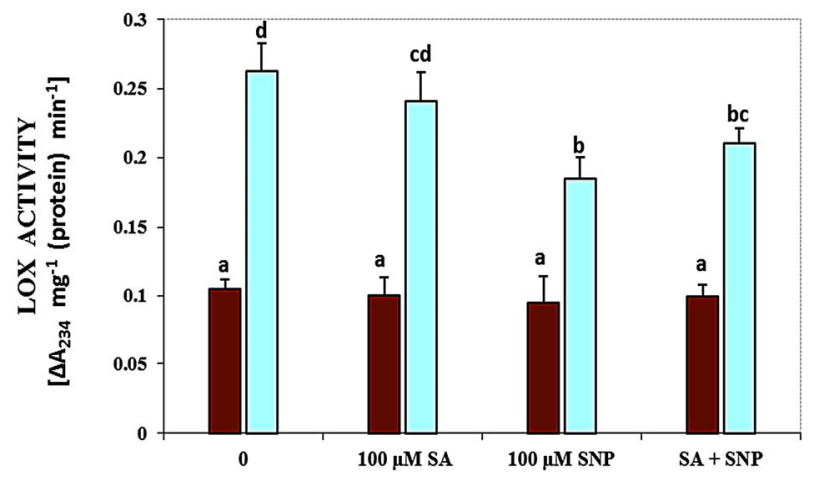

(a)

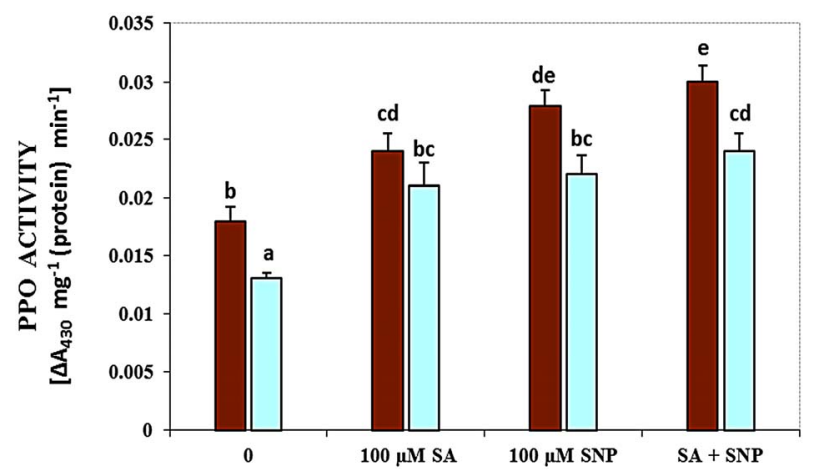

(c) enzyme decreased in the presence of $100 \mathrm{mM} \mathrm{NaCl}$. In the presence of exogenous SA and/or NO donor SNP, the activity of PAL considerably increased subjected to 100 $\mathrm{mM} \mathrm{NaCl}$. The application of SA with SNP could significantly increase PAL activity under salinity.

\section{Discussion}

The results indicated that the content of $\mathrm{Na}^{+}$was increased in the root and shoot of G. $\max$ under salinity (Table 1), while $\mathrm{K}^{+}$and $\mathrm{Ca}^{2+}$ was decreased. However, excessive soluble ions such as sodium and chloride are harmful to most plants, including all major crops [20]. It has been reported that $\mathrm{Na}^{+}$is an inhibitory ion for cytosolic processes [21]. There is a direct relationship between the contents of $\mathrm{Na}^{+}$in root and shoot with applied concentration of $\mathrm{NaCl}$. The results showed that increase in the $\mathrm{Na}^{+}$content is correlated to decrease in $\mathrm{K}^{+}$uptake. The $\mathrm{Na}^{+}$uptake might be mediated by $\mathrm{K}^{+}$channel and non-selective cation channels [22]. $\mathrm{K}^{+}$is a necessary ion to translate mRNA to protein thought coupling ribosome subunits. To investigate the effects of exogenous SA and $\mathrm{NO}$ donor on $\mathrm{Na}^{+}, \mathrm{K}^{+}$and $\mathrm{Ca}^{2+}$ uptake, were measured the contents of $\mathrm{Na}^{+}, \mathrm{K}^{+}$and $\mathrm{Ca}^{2+}$ in $G$. max. The results showed that treatment with SA, SNP and especially the combination of SA and SNP significantly decreased the

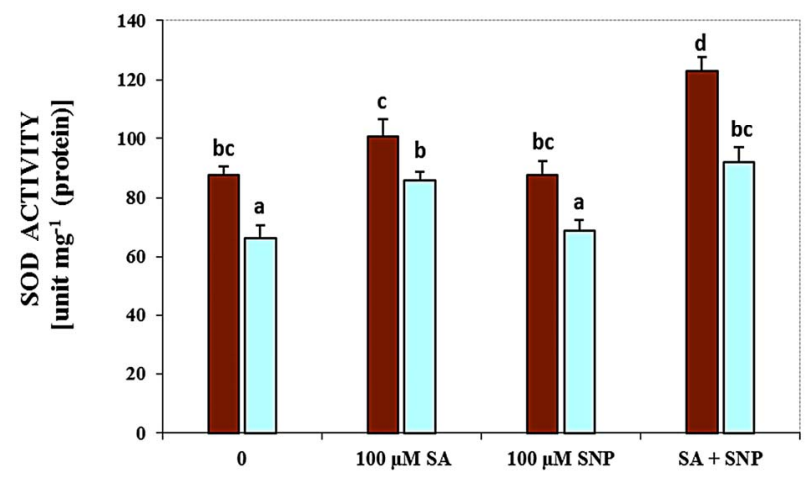

(b)

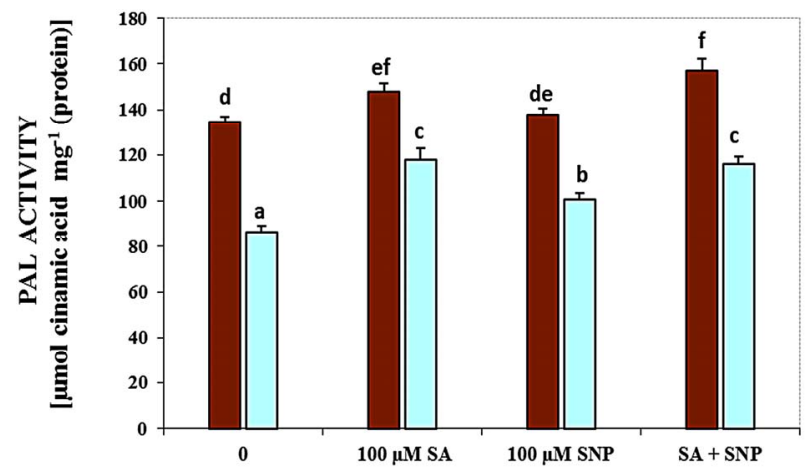

(d)

Figure 3. Effects of SA, SNP, and SA + SNP on the activity of LOX (a), SOD (b), PPO (c) and PAL (d) in soybean under saline and non-saline conditions. 
$\mathrm{Na}^{+}$content of shoot under $\mathrm{NaCl}$ salinity, but application of SA and/or NO donor had no significant effect. In contrast, externally application of SA, SNP and SA + SNP in the same condition enhanced the contents of $\mathrm{K}^{+}$in the root of soybean plants. Moreover, treatment with SA + SNP could increase the contents of $\mathrm{Ca}^{2+}$ in the root and shoot of soybean plants under $100 \mathrm{mM} \mathrm{NaCl}$. Enhancing effects of $100 \mu \mathrm{M} \mathrm{SA}$ and/or $100 \mu \mathrm{M}$ SNP in the $\mathrm{K}^{+}$and $\mathrm{Ca}^{2+}$ uptake reduced the $\mathrm{Na}^{+}$Content and the $\mathrm{Na}^{+} / \mathrm{K}^{+}$ ratio significantly. Treatment with exogenous $\mathrm{SA}$ and NO donor maintained a lower ratio of $\mathrm{Na}^{+} / \mathrm{K}^{+}$in $\mathrm{NaCl}$ stressed plants. The results suggested that NO might confer salt tolerance in $G$. max by preventing both oxidative membrane damage and translocation of $\mathrm{Na}^{+}$from the root to shoot that coincident with the obtained results by Guo and coworkers [23]. It has been reported that Arabidopsis mutant Atnoal with an impaired in vivo NO synthase (NOS) activity and a reduced endogenous NO level was more sensitive to $\mathrm{NaCl}$ stress in comparison with wild type. Atnoal mutants displayed a greater $\mathrm{Na}^{+} / \mathrm{K}^{+}$ ratio in shoot than wild type when exposed to $\mathrm{NaCl}$, but SNP treatment attenuated this elevation of $\mathrm{Na}^{+} / \mathrm{K}^{+}$ratio [24]. Also, It is reported that NO enhanced salt tolerance in maize seedlings, through increasing $\mathrm{K}^{+}$accumulation in root, leaves and sheathes, while decreased $\mathrm{Na}^{+}$accumulation [25]. Furthermore, treatment with SA could decrease the $\mathrm{Na}^{+}$uptake, while increased the uptake of $\mathrm{K}^{+}$ and $\mathrm{Ca}^{2+}$ in Catha edulis [26]. $\mathrm{Ca}^{2+}$ is widely accepted as an important second messenger in the intracellular signal transduction from the cell surface to internal compartments of the cell [27]. $\mathrm{Ca}^{2+}$ alleviates $\mathrm{Na}^{+}$toxicity through different mechanisms, including the control of $\mathrm{Na}^{+} / \mathrm{K}^{+}$ selective accumulation and others that are now being elucidated [28].

Experiment showed that exogenous application of SA, SNP and SA + SNP increased NaCl-induced reduction in the germination of soybean seeds. It was suggested presowing seed treatment with SA leads to an activation of germination and seedling growth [29]. There is a growing body of evidence that NO plays a role in seed dormancy and germination, but its mechanism of action at the cellular level is unknown yet. NO scavengers have also been used to implicate NO as the effective component when dormancy is broken by a range of N-containing compounds, including NO donors. For example, cPTIO prevented germination of Arabidopsis seeds that would otherwise be induced by SNP [30].

Leaf flavonoids and anthocyanins act as the scavenger of free radicals which protect cells against oxidative stress induced by the damaging effects of reactive oxygen species [31]. Morever, flavonoids are able to chelate iron atom and prevent Fenton reaction [32]. Exposure to $\mathrm{NaCl}$ salinity, treatment with SA, SNP and SA + SNP could enhance the content of flavonoids and anthocyanins in leaves to confer resistance of soybean seedlings to salinity. The results suggested that the role of SA + SNP in increasing these pigments was the more effective than of treatment with SA and NO donor SNP alone. The results have been suggested that the application of SA and SNP can affect the biosynthesis pathways of these pigments and counteract $\mathrm{NaCl}$-induced stress [33].

It has been reported that stimulation of LOX activity under stress conditions reflects higher lipolytic activity in membranes and oxidation of membrane-bound fatty acids by causing propagation of lipid peroxidation [34]. It has been showed that LOX activity was increased in the presence of $100 \mathrm{mM} \mathrm{NaCl}$. In addition, an inhibiting effect of LOX activity was found in soybean plants treated with SNP and SA + SNP under salt stress. These results provide evidence that SA and especially NO donor may reduce LOX activity to against lipid peroxidation and membrane damage produced by $\mathrm{NaCl}$ salinity. It has been suggested that NO-activated antioxidative systems protected membrane lipids against peroxidation by interacting with lipid peroxyl radicals or by blocking LOX activity [35].

Salt stress often leads to increased production of ROS in plants, including $\mathrm{H}_{2} \mathrm{O}_{2}$, hydroxyl radicals $\left(\mathrm{OH}^{-}\right)$and superoxide anions $\left(\mathrm{O}_{2}^{-}\right)$[36]. The superoxide dismutase (SOD) is one of the most important enzymes of the antioxidant defense system in the cells of all organisms. It has been observed a progressive increase in SOD activity to SA + SNP in the absence of salinity and by SA and SA + SNP under $100 \mathrm{mM} \mathrm{NaCl}$. In addition, the enhanced activities of SOD due to NO donor application might have been one of the factors contributing to improved growth in soybean plants under saline conditions. Further results proved that interaction of SA with NO donor significantly enhanced the activities of SOD and catalase (CAT), both of which separately contributed to the delay of and $\mathrm{H}_{2} \mathrm{O}_{2}$ accumulation in wheat leaves under salt stress $[2,37]$. Therefore, it has been conclude that the protective effect of SA and NO in stressed soybean roots may be partly due to the stimulation of SOD activity and/or direct scavenging of the superoxide anion. It has been suggested SA-induced SOD activation in wheat plants was consistent with the results obtained with other plants such as maize, cucumber and rice [29].

It is reported that treatment of cowpea genotypes with SA results in the induction of PAL activity and quantitative change in polyphenoloxidase (PPO) isozyme patterns and also increase in the level of endogenous SA [38]. They as well showed the increase in activity of PPO can be attributed to minimize production of ROS. The application of SA, NO donor and the combination SA with SNP in this research could enhance the activity of 
PPO under salt and non-saline stress. NO-derived induction for phenylalanine ammonia lyase (PAL) gene was shown in tobacco and soybean [39]. Nitric oxide also affects the expression of numerous plant genes, including those that encode PAL and pathogenesis related 1 (PR1). Because the accumulation of PAL has been detected in tobacco cell suspensions that were treated with a membrane-permeable analogue of cGMP, and taking into account that the induction of PAL in tobacco suspension cells by NO can be suppressed by several inhibitors of guanylate cyclase. Moreover, It is thought the activation of some of NO-dependent defense genes be mediated by cGMP [39]. PAL is known to play a key role in the synthesis of phenolic substances necessary for lignification [40]. It is shown that SA increased the activity of PAL in the roots of wheat seedlings. Therefore, the involvement of SA in the acceleration of lignification of cell walls which in turn might have contributed to an increase in salt resistance of wheat plants was suggested [29].

\section{Conclusion}

Salt stress often leads to increased production of ROS in plants, while application of SA, NO donor and especially the crosstalk between SA with SNP reduce the damaging effects of salinity.

\section{Acknowledgements}

We are grateful to the coworkers of the laboratory of lahijan, science and research branch, Islamic Azad University, for their support.

\section{REFERENCES}

[1] M. Sharifi, M. Ghorbanli and E. Ebrahimzadeh, "Improved Growth of Salinity Stressed Soybean after Inoculation with Salt Pre-Treated Mycorrhizal Fungi," Journal of Plant Physiology, Vol. 164, No. 9, 2007, pp. 11441151. doi:10.1016/j.jplph.2006.06.016

[2] M. Simaei, R. A. Khavari-Nejad, S. Saadatmand, F. Bernard and F. Fahimi, "Interactive Effects of Salicylic Acid and Nitric Oxide on Soybean Plants under $\mathrm{NaCl}$ Salinity," Russian Journal of Plant Physiology, Vol. 58, No. 5, 2011, pp. 783-390. doi:10.1134/S1021443711050220

[3] E. Horvath, G. Szalai and T. Janda, "Induction of Abiotic Stress Tolerance by Salicylic Acid Signaling," Journal of Plant Growth Regulation, Vol. 26, No. 3, 2007, pp. 290300. doi:10.1007/s00344-007-9017-4

[4] I. Raskin, "Role of Salicylic Acid in Plants," Annual Review of Plant Physiology and Plant Molecular Biology, Vol. 43, 1992, pp. 439-463. doi:10.1146/annurev.pp.43.060192.002255

[5] A. Metwally, I. Finkemeier, M. Georgi and K. J. Dietz, "Salicylic Acid Alleviates the Cadmium Toxicity in Barley Seedlings," Plant Physiology, Vol. 132, No. 1, 2003, pp. 272-281. doi:10.1104/pp.102.018457

[6] M. Waseem, H. R Athar and M. Ashraf, "Effect of Salicylic Acid Applied through Rooting Medium on Drought Tolerance of Wheat," Pakistan Journal of Botany, Vol. 38, No. 4, 2006, pp. 1127-1136.

[7] M. Arfan, H. R. Athar and M. Ashraf, "Does Exogenous Application of Salicylic Acid through the Rooting Medium Modulate Growth and Photosynthetic Capacity in Two Differently Adapted Spring Wheat Cultivars under Salt Stress?" Journal of Plant Physiology, Vol. 164, No. 6, 2007, pp. 685-694. doi:10.1016/j.jplph.2006.05.010

[8] M. Arasimowicz and J. Floryszak-Wieczorek, "Nitric Oxide as a Bioactive Signaling Molecule in Plant Stress Responses," Plant Science, Vol. 172, No. 5, 2007, pp. 876-887. doi:10.1016/j.plantsci.2007.02.005

[9] A. I. Lopez-Carrion, R. Castellano, M. A. Rosales, J. M. Ruiz and L. Romero, "Role of Nitric Oxide under Saline Stress: Implications on Proline Metabolism," Biologia Plantarum, Vol. 52, No. 3, 2008, pp. 587-591. doi:10.1007/s10535-008-0117-1

[10] L. Lamattina, C. Garcia-Mata, M. Graziano and G. Pagnussat, "Nitric Oxide: The Versatility of an Extensive Signal Molecule," Annual Review of Plant Biology, Vol. 54, 2003, pp. 109-136. doi:10.1146/annurev.arplant.54.031902.134752

[11] D. R. Hoagland and D. I. Arnon, "The Water-Culture for Growing Plants without Soil," Agricultural Experiment Station Circulation, Vol. 374, 1957.

[12] J. D. Maguire, "Speed of Germination-Aid in Selection and Evaluation for Seedling Emergence and Vigor," Crop Science, Vol. 2, No. 2, 1962, pp. 176-177. doi:10.2135/cropsci1962.0011183X000200020033x

[13] D. T. Krizek, S. J. Britz and R. M. Mirecki, "Inhibitory Effects of Ambient Levels of Solar UV-A and UV-B Radiation on Growth of cv. New Red Fire Lettuce," Physiologia Plantarum, Vol. 103, No. 1, 1998, pp. 1-7.

[14] G. J. Wagner, "Content and Vacuole/Extra Vacuole Distribution of Neutral Sugars, Free Amino Acids, and Anthocyanins in Protoplast," Plant Physiology, Vol. 64, No. 1, 1979, pp. 88-93. doi:10.1104/pp.64.1.88

[15] M. M. Bradford, "A Rapid and Sensitive Method for Quantitation of Microgram Quantities of Protein Utilizing the Principle of Protein-Dye Binding," Analytical Biochemistry, Vol. 72, No. 1-2, 1976, pp. 248-254.

[16] A. Doderer, I. Kokkelink, S. Van der Veen, B. Valk, A. Schram and A. Douma, "Purification and Characterization of Two Lipoxygenase Isoenzymes from Germinating Barley," Biochimica et Biophysica Acta (BBA), Vol. 1120, No. 1, 1992, pp. 97-104. doi:10.1016/0167-4838(92)90429-H

[17] C. N. Giannopolitis and S. K. Ries, "Superoxide Dismutases. I. Occurrence in Higher Plants," Plant Physiology, Vol. 59, No. 2, 1977, pp. 309-314. doi:10.1104/pp.59.2.309

[18] J. Raymond, N. Rakariyatham and J. L. Azanza, "Purification and Some Properties of Polyphenoloxidase from Sunflower Seeds," Phytochemistry, Vol. 34, No. 4, 1993, 
pp. 927-931. doi:10.1016/S0031-9422(00)90689-7

[19] N. Ochoa-Alejo and J. E. Gomez-Peralta, "Activity of Enzymes Involved in Capsaicin Biosynthesis in Callus Tissue and Fruits of Chili Pepper (Capsicum annuum L.)," Journal of Plant Physiology, Vol. 141, No. 2, 1993, pp. 147-152. doi:10.1016/S0176-1617(11)80751-0

[20] V. Chinnusamy, J. Zhu and J. K. Zhu, "Salt Stress Signaling and Mechanisms of Plant Salt Tolerance," Genetic Engineering, Vol. 27, 2006, pp. 141-177. doi:10.1007/0-387-25856-6 9

[21] J. K. Zhu, J. P. Liu and L. M. Xiong, "Genetic Analysis of Salt Tolerance in Arabidopsis: Evidence for a Critical Role of Potassium Nutrition," The Plant Cell, Vol. 10, No. 7, 1998, pp. 1181-1191.

[22] R. Serrano, J. M. Mulet, G. Rios, J. A. Marquez, I. F. de Larriona, M. P. Leube, I. Mendizabal, A. Pascual-Ahuir, M. R. R. Proft and C. Montesinos, "A Glimpse of the Mechanism of Ion Homeostasis during Salt Stress," Journal of Experimental Botany, Vol. 50, Special Issue, 1999, pp. 1023-1036.

[23] Y. Guo, Z. Tian, D. Yan, J. Zhang and P. Qin, "Effects of Nitric Oxide on Salt Stress Tolerance in Kosteletzkya virginica," Life Science Journal, Vol. 6, 2009, pp. 67-75.

[24] M. G. Zhao, Q. Y. Tian and W. H. Zhang, "Nitric Oxide Synthase-Dependent Nitric Oxide Production Is Associated with Salt Tolerance in Arabidopsis," Plant Physiol$o g y$, Vol. 144, No. 1, 2007, pp. 206-217. doi:10.1104/pp.107.096842

[25] Y. Y. Zhang, J. Liu and Y. L. Liu, "Nitric Oxide Alleviates the Growth Inhibition of Maize Seedlings under Salt Stress," Journal of Plant Physiology and Molecular Biology, Vol. 30, No. 4, 2004, pp. 455-459.

[26] A. M. A. Al-Hakimi, "Effect of Salicylic Acid on Biochemical Changes in Wheat Plants under Khat Leaves Residues," Plant, Soil and Environment, Vol. 54, No. 7, 2008, pp. 288-293.

[27] A. C. Scott, N. S. Allen, "Changes in Cytosolic pH within Arabidopsis Root Columella Cells Play a Key Role in the Early Signaling Pathway for Root Gravitropism," Plant Physiology, Vol. 121, No. 4, 1999, pp. 1291-1298. doi:10.1104/pp.121.4.1291

[28] L. Rubio, A. Rosado, A. Linares-Rueda, O. Borsani, M. J. Garcia-Sanchez, V. Valpuesta, J. A. Fernandez and M. A. Botella, "Regulation of $\mathrm{K}^{+}$Transport in Tomato Roots by the $T S S_{1}$ Locus, Implications in Salt Tolerance," Plant Physiology, Vol. 134, No. 1, 2004, pp. 452-459. doi:10.1104/pp.103.030361

[29] F. M. Shakirova and D. R. Sahabutdinova, "Changes in the Hormonal Status of Wheat Seedlings Induced by Salicylic Acid and Salinity," Plant Science, Vol. 164, No. 3, 2003, pp. 317-322. doi:10.1016/S0168-9452(02)00415-6

[30] P. C. Bethke, I. G. L. Libourel, V. Reinohl and R. L. Jones,
"Sodium Nitroprusside, Cyanide, Nitrite, and Nitrate Break Arabidopsis Seed Dormancy in a Nitric Oxide-Dependent Manner," Planta, Vol. 223, No. 4, 2006, pp. 805-812.

[31] G. Schaller and J. Kieber, "Ethylene," American Society of Plant Biologists, 2002, pp. 1-17.

[32] L. Popova, T. Pancheva and A. Uzunova, "Salicylic Acid: Properties, Biosynthesis and Physiological Role," Bulgarian Journal of Plant Physiology, Vol. 23, 1997, pp. 85-93.

[33] H. S. Chae, F. Faure and J. J. Kieber, "The eto1, eto2, and eto3 Mutations and Cytokinin Treatment Increase Ethylene Biosynthesis in Arabidopsis by Increasing the Stability of ACS Protein," The Plant Cell, Vol. 15, No. 2, 2003, pp. 545-559. doi:10.1105/tpc.006882

[34] A. Molassiotis, G. Tanoug and A. Patakas, "Effects of 4Month Fe Deficiency Exposure on $\mathrm{Fe}^{2+}$ Reduction Mechanism, Photosynthetic Gas Exchange Chlorophyll Fluorescence and Antioxidant Defense in Two Peach Rootstocks Differing in $\mathrm{Fe}^{2+}$ Deficiency Tolerance," Journal of Plant Nutrition, Vol. 25, 2005, pp. 843-860.

[35] M. V. Beligni, A. Fath, P. C. Bethke, L. Lamattina and R. L. Jones, "Nitric Oxide Acts as an Antioxidant and Delays Programmed Cell Death in Barley Aleurone Layers," Plant Physiology, Vol. 129, 2002, pp. 1642-1650. doi:10.1104/pp.002337

[36] C. Sudhakar, A. Lakshmi and S. Giridarakumar, "Changes in Antioxidant Enzyme Efficacy in Two High Yielding Genotypes of Mulberry (Morus alba L.) under $\mathrm{NaCl} \mathrm{Sa-}$ linity," Plant Science, Vol. 61, 2001, pp. 613-619 doi:10.1016/S0168-9452(01)00450-2

[37] R. Haihua, S. Wenbiao, Y. E. Maobing and X. U. Langlai, Protective Effects of Nitric Oxide on Salt Stress-Induced Oxidative Damage to Wheat (Triticum aestivum L.) Leaves," Chinese Science Bullitin, Vol. 47, 2002, pp. 677-681.

[38] A. Chandra and R. Saxena, "Change in Phenylalanine Ammonia Lyase Activity and Isozyme Patterns of Polyphenol Oxidase and Peroxidase by Salicylic Acid Leading to Enhance Resistance in Cowpea against Rhizoctonia solani," Acta Physiologiae Plantarum, Vol. 29, No. 4, 2007, pp. 361-367. doi:10.1007/s11738-007-0045-2

[39] J. Durner, D. Wendehenne and D. F. Klessig, "Defense Gene Induction in Tobacco by Nitric Oxide, Cyclic GMP, and Cyclic ADP-Ribose," Proceedings of the National Academy of Sciences, Vol. 95, No. 17, 1998, pp. 1032810333. doi:10.1073/pnas.95.17.10328

[40] G. L. Shadle, S. V. Wesley, K. L. Korth, F. Chen, C. Lamb and R. A. Dixon, "Phenylpropanoid Compounds and Disease Resistance in Transgenic Tobacco with Altered Expression of L-Phenylalanine Ammonia-Lyase," Phytochemistry, Vol. 64, No. 1, 2003, pp. 153-161. doi:10.1016/S0031-9422(03)00151-1 


\section{Abbreviations}

CAT: Catalase;

FW: Fresh weight;

GP: Germination percentage;

GSNO: S-nitrosoglutathione;

LOX: Lipoxygenase;
NOS: Nitric oxide synthase;

PAL: Phenylalanine ammonia lyase;

PPO: Polyphenol oxidase;

SA: Salicylic acid;

SNP: Sodium nitroprusside;

SOD: Superoxide dismutase. 